\title{
Survival analysis of companies' delisting time in Indonesian stock exchange using Bayesian multiple-period logit approach
}

\author{
Dedy Dwi Prastyo*, Titis Miranti, Nur Iriawan \\ Department of Statistics, Institut Teknologi Sepuluh Nopember, Kampus ITS-Sukolilo, Surabaya 60111, Indonesia \\ * Corresponding author: dedy-dp@statistika.its.ac.id
}

\section{Article history}

Received 21 October 2017

Accepted 8 November 2017

\begin{abstract}
Multiple-period logit model is equivalent to hazard model. This model is able to accommodate time varying predictor. In this work, the parameters of multiple-period model are estimated by using Bayesian inferences. There are three prior distributions used, i.e. improper uniform distribution, multivariate normal distribution, and Cauchy distribution. Criterion which is used to evaluate the proposed technique is C-index. The proposed method is applied to model the delisting time of companies listed in Indonesian Stock Exchange. The survival (delisting) time is driven by firmspecific predictors, i.e. financial ratios, that are calculated from quarterly financial report of companies in manufacturing sector span from the first quarter of 1990 until the third quarter of 2015. Two macroeconomic indicators are also considered as predictors. The empirical results show that the most appropriate prior is multivariate normal distribution. In addition, the proposed model is applied on windowing scheme by reducing the interval time as window in which the model estimator perform by its best.
\end{abstract}

Keywords: Survival, multiple-period logit, Bayesian, delisting, C-index

\section{INTRODUCTION}

Delisting is a term to explain the removing of a company's share from a stock exchange. It is conducted to protect investors when the company has failed to fulfill its obligations as public company. Therefore, the calculation of probability to default becomes very important. From statistical point of view, the survival analysis can be used to calculate the delisting probability. The dynamics of performance of a company represented by its financial ratios demand that the survival model used must accommodate the time varying covariates (Prastyo and Haerdle, 2014). One of the discrete approaches for such a case is multiple-period logit. It expressed more consistently than the static model (Shumway, 2001). The logit model itself is widely applied in many areas, for example Haerdle and Prastyo (2014) who applied logit model for credit scoring and Suhartono et al. (2016) who employed logit model for evaluating academic achievement of scholars.

The multiple-period logit model is the expansion of logistic regression model. It can accommodate the time dependent covariates within the model. Several papers discuss about multiple-period logit approach. It predicted the bankruptcy of company better than discriminant analysis on NYSE and AMEX company from 1962 until 1992 (Shumway, 2001). Further, multiple-period logit model is applied to predict the bankruptcy of commercial banks in America in period 1980-1992 (Cole and Wu, 2009). It compared the single period probit model and multiple-period logit model. The result is known that the multiple-period logit model gave better prediction with accuracy $93.12 \%$ compared to $72.34 \%$.

Iriawan (2005) analyzed financial ratio data using logistic regression and Bayesian approach. The analysis was applied on companies listed in Surabaya Stock Exchange. It informed the rank of share, shifting level for share, and calculated the contribution of each financial ratio to financial health level of share. Bayesian approach updates the information within data with prior knowledge. Ismail et al. (2012) compared the estimation of Cox proportional hazard model (Cox PHM) using frequentist and Bayesian approaches. Wong et al. (2005) applied Bayesian approach to analyze clustered intervalcencored data.

This research is aimed to employ the Bayesian inference for multiple-period logit model which is used to calculate the probability to delist for manufacture companies listed in the Indonesia Stock Exchange (IDX). There are fifteen financial ratios calculated from financial report and two macroeconomic indicators as predictors spanning from the first quarter of 1990 until the third quarter of 2015.

This paper is constructed as follows. First, introduction section descibes the background of this research. The next two sections are devoted for methodology and empirical results. The last section concludes the findings of this resaearch.

\section{METHOD}

\section{Survival Analysis}

Random variable that is analyzed in survival analysis is the time until an event occurs $(T)$. The meaning of event can be defined based on case, for example time to delist from stock exchange, time to bankrupt, or others. Survival analysis becomes a main method developed by many researchers because it has censoring status that differs from other typical data. Commonly, an event $(y)$ is concerned about failure denoted by $y=1$, otherwise the object survive or censored denoted by $y=0$. An observation is considered as censored 
if the event does not happen until the research period ends or it is lost to be followed up (Kleinbaum and Klein, 2012).

Survival function represents the probability to survive until certain time $t$ or more that can be expressed in (1),

$$
S(t)=P(T>t)=1-P(T \leq t)=1-F(t),
$$

where $T$ denotes the failure time and $F(t)$ is its cumulative distribution function. Survival function has relation to hazard function describing instantaneously failure rate given an object survive until time $t$. This function can be expressed as in (2),

$$
h(t)=\lim _{\Delta t \rightarrow 0} \frac{P(t \leq T<t+\Delta t \mid T \geq t)}{\Delta t} .
$$

Denoting $H(t)$ as cumulative hazard, the relationship between survival function and hazard function is expressed as:

$$
S(t)=\exp (-H(t))
$$

Kaplan-Meier (KM) curve describes the intercourse between survival function and survival time. KM curve consists of two axes, i.e. the vertical axis that denotes the estimated survival function and the horizontal axis labels survival time. Fig. 1 is KM curves for group 1 and group 2. The KM curve for group 1 is consistently higher than $\mathrm{KM}$ curve for group 2. This means that group 1 has more time to survive than group 2 . The difference between these two survival functions can be evaluated statistically using log-rank test.

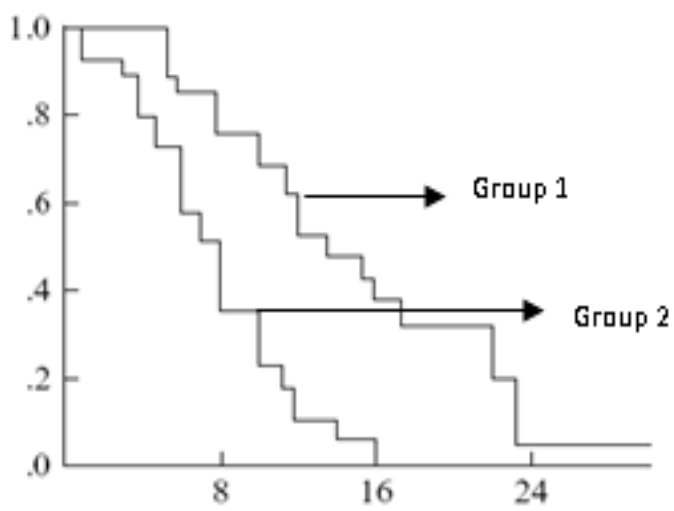

Fig. 1 Kaplan-Meier curve for two group.

\section{Cox proportional hazard model (Cox PHM)}

Cox PHM is very popular in survival analysis as a semiparametric approach. Let $h(t, \mathbf{x})$ be hazard function at time $t$ and $\mathbf{x}$ are predictors. The hazard function can be expressed by (4) as:

$$
h(t, \mathbf{x})=h_{0}(t) \exp \left(\boldsymbol{\beta}^{\prime} \mathbf{x}\right)
$$

with $h_{0}(t)$ as baseline hazard. Exponential function is imposed on predictor variables $\mathbf{x}=\left(x_{1}, x_{2}, \ldots, x_{d}\right)^{\prime}$ associated with corrrespoding coefficients $\boldsymbol{\beta}^{\prime}=\left(\beta_{1}, \beta_{2}, \ldots, \beta_{d}\right)$ as its corresponding coefficient (Kleinbaum and Klein, 2012). The Cox PH assumes proportional hazard, so the predictors are independent on time. The proportional hazard assumption is checked visually using KM curve as illustrated in Fig. 1 and statistically using log-rank test.

The Cox PHM is semi-parametric model since the baseline hazard is not nesessarily specified. In parametric approach, the baseline hazard has specific form that depend on the distribution of survival time. Several simulation studies use parametric approach to generate survival time (Bender et al., 2005; Khoiri et al., 2017).

\section{Bayesian approach for multiple-period logit}

The multiple-period logit model is equivalent with hazard model in discrete time given that the observation is independent. The hazard function is expressed as in (5),

$$
h\left(t_{i}, \mathbf{x}_{i} ; \boldsymbol{\beta}\right)=F\left(t_{i}, \mathbf{x}_{i} ; \boldsymbol{\beta}\right)=P\left(T \leq t \mid y_{i}=1\right),
$$

where $y_{i}$ is equal to one if the company fails at time $t_{i}$, otherwise it is equal to zero. The likelihood model for multiple-period logit model can be expressed as (6),

$$
L=\prod_{i=1}^{n}\left(h\left(t_{i}, \mathbf{x}_{i} ; \boldsymbol{\beta}\right)^{y_{i}} \prod_{j<t_{i}}\left[1-h\left(t_{i}, \mathbf{x}_{i} ; \boldsymbol{\beta}\right)\right]\right)
$$

with $\boldsymbol{\beta}$ denotes vector of parameters and $\mathbf{x}_{i}$ denotes the predictor variables for observation $i$. Based on (6), if the company is not delisted, the second term is raised to power $\left(1-y_{i}\right)$ such that Eq. (6) is rewritten as (7),

$$
L=\prod_{i=1}^{n}\left(h\left(t_{i}, \mathbf{x}_{i} ; \boldsymbol{\beta}\right)^{y_{i}}\left(1-h\left(t_{i}, \mathbf{x}_{i} ; \boldsymbol{\beta}\right)\right)^{1-y_{i}}\right)
$$

Bayesian approach comprehends a parameter as random variable that has a prior distribution. It requires prior information to propose parameter value. Multiplication of prior and likelihood delivers posterior (Wong et al., 2005). There are several kinds of prior, i.e. conjugate and non-conjugate prior, proper and improper prior, informative and non-informative prior, and pseudo prior (Box and Tiao, 1992). Bayesian approach requires a prior distribution of parameters within the model, for example employ the default prior distribution for logistic regression and other multiple regressions. The research suggested using the Cauchy distribution as a prior distribution on all parameters in logistic regression. The Cauchy distribution used is centered at 0 and 2.5 for scale parameter (Gelman et al., 2008).

\section{Performance measure}

Concordance index (C-index) as a performance measure is quite useful because it can be used to compare the performance of semiparametric and non-parametric approach in survival analysis. The Cindex as calculated in Eq. (8) can measure concordance between predicted prognostic index and observed survival time (Mahjub et al., 2016, Van Belle et al., 2010, and Van Belle et al., 2011):

$$
c_{i, j>i}(H(t))=\frac{\sum_{i=1}^{n} \sum_{j>i}^{n} v_{i j} I\left(\left[\left(1-H\left(t, \mathbf{x}_{i}\right)\right)-\left(1-\left(t, \mathbf{x}_{i}\right)\right)\right]\left(t_{j}-t_{i}\right)>0\right)}{\sum_{i=1}^{n} \sum_{j>i}^{n} v_{i j}}
$$

The indicator function $I$ is defined as follows:

$$
I= \begin{cases}1, & \text { if }\left[\left(1-H\left(t, \mathbf{x}_{i}\right)\right)-\left(1-\left(t, \mathbf{x}_{i}\right)\right)\right]\left(t_{j}-t_{i}\right)>0 \\ 0, & \text { otherwise }\end{cases}
$$

with $v_{i j}$ is comparator indicator, $H\left(t, \mathbf{x}_{i}\right)$ is cumulative hazard function for observation $i$, and $t$ is survival time.

\section{RESULTS AND DISCUSSION}

\section{Data and variable}

The raw data used in this research are quarterly financial reports of 77 companies, with 4 firms are default, downloaded from the IDX website and Indonesia Capital Market Directory (ICMD) from the first quarter of 1990 to third quarter of 2015. The financial ratios listed in Table 1 are then calculated from those financial reports.

The variables of interest consist response variables and predictor. The response is survival time (in quarter) denotes the time until a company is delisted form IDX. The censorship status of each 
company is denoted as $y$, i.e. it has value 0 if it is censored and 1 for the delisted company.

Table 1 Predictors variables.

\begin{tabular}{lll}
\hline Variable & Ratio & \multicolumn{1}{c}{ Description } \\
\hline$x_{1}$ & CR & Current Ratio \\
$x_{2}$ & DAR & Debt to Asset Ratio \\
$x_{3}$ & DER & Debt to Equity Ratio \\
$x_{4}$ & ROA & Return on Asset \\
$x_{5}$ & ROE & Return on Equity \\
$x_{6}$ & GPM & Gross Profit Margin \\
$x_{7}$ & OPM & Operating Profit Margin \\
$x_{8}$ & NPM & Net Profit Margin \\
$x_{9}$ & EBITA & Earnings Before Income Tax to Asset \\
$x_{10}$ & STA & Sales to Total Asset \\
$x_{11}$ & ETD & Earning to Debt \\
$x_{12}$ & WCA & Working Capital to Total Asset \\
$x_{13}$ & WCLTD & Working Capital to Long Term Debt \\
$x_{14}$ & REA & Retained Earnings to Total Asset \\
$x_{15}$ & SFA & Sales to Fixed Asset \\
$x_{16}$ & IHSG & Indonesian Composite Index \\
$x_{17}$ & BI Rate & Bank Indonesia's Interest Rate \\
\hline
\end{tabular}

\section{Data characteristic and Kaplan Meier Curve}

The characteristics of manufacture companies listed in IDX are visualized by two KM curves in Fig. 2 and Fig. 3. The Fig. 2 displays $\mathrm{KM}$ curve for all companies in manufacture sector for 103 quarters. It informs that all sectors have probability to survive above $80 \%$. Fig. 3 displays the KM curve for each subsector. The red line is survival curve for companies belong to basic chemical industry subsector, blue line is survival curve of multifarious industry subsector and green line is survival curve of consumer goods industry subsector. The KM curve interprets that survival probability in all subsectors are relatively the same, it is above $75 \%$. Basic chemical industry and consumer goods industry subsector coincided and constant from the beginning of observation to the 74-th quarter. In 50-th quarter, the survival probability of multifarious industry decreases for the first time. Consumer goods industry subsector decreases sharper than the other sectors in 74-th quarter and it decreases again in 80-th quarter.

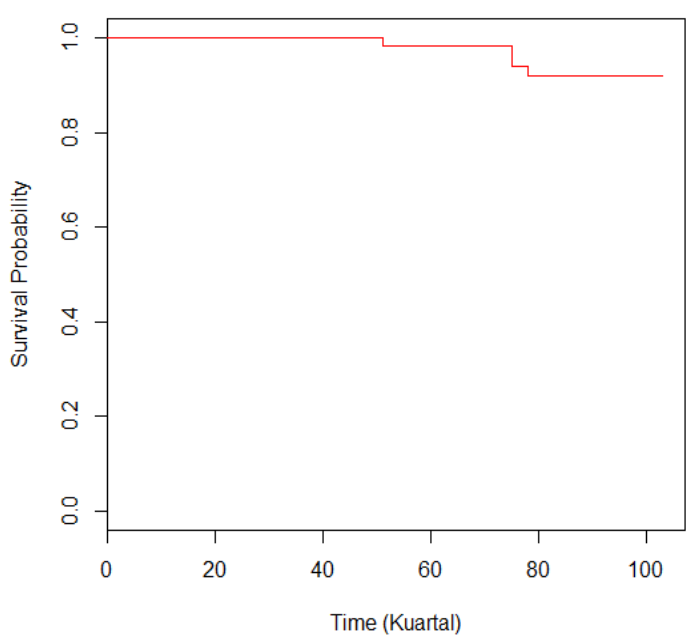

Fig. 1 Kaplan-Meier curve all manufacturing companies.
The log rank test produces statistic value of 2.2 that correspond to $p$-value 0.340 . In the $90 \%$ confidence interval, the decision fails to reject null hypothesis which means that there is no difference of the survival curves between sub-sectors. The higher survival probability of company establishes lower delisted probability. Fig. 2 and Fig. 3 explain survival probability in two ways, whereas both express that survival probability of companies are good.

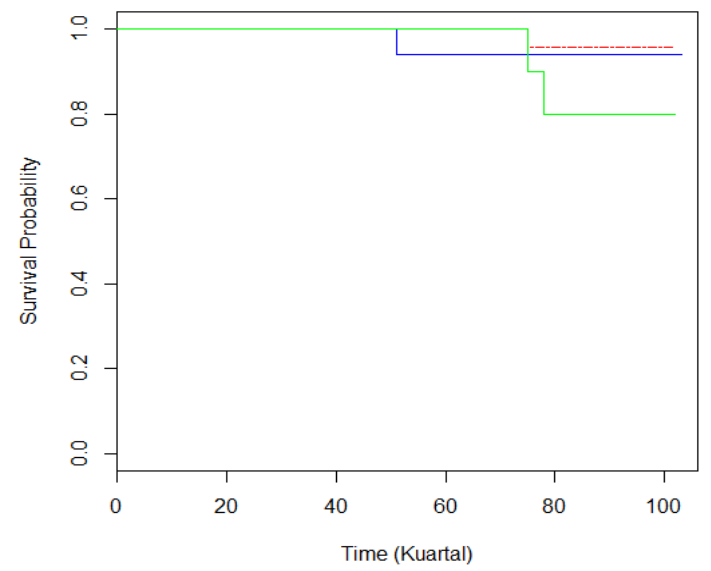

Fig. 2 Kaplan-Meier curve for companies at each subsector.

\section{Parameter estimation}

The parameters of the model are estimated by using MCMClogit function available from the library MCMCPaCk in R software. The two out of three prior distributions used in this study are the default of the $M C M C l o g i t$ function, i.e. uniform improper distribution and multivariate normal distribution. Each prior distribution carries out the same number of MCMC, thin values, and burn-in. Number of thin is 500 with the number of MCMC is 200,000 , and number of burn-in is 5,000 .

If improper uniform prior distribution is used, thus MCMClogit function is set with $b 0=0, B 0=0$ and user.prior.density is NULL as inputs. If the inputs values $b 0$ and $B 0$ are not equal to zero and other remain inputs (by default), the prior distribution used is multivariate normal. In this study, $b 0$ for multivariate normal distribution parameters are enumerated from the estimate obtained from univariate GLM function for each. Therefore, the $b 0$ is a vector with row number as much as a covariate and its column is one. The diagonal matrix $B 0$ has diagonal values $(1 /$ s.e.), where the s.e. is the standard error of the estimate $b 0$.

The third prior distribution that is employed is Cauchy distribution invoked from dcauchy function in $\mathrm{R}$ that is set to write the userdefined prior function so-called log.prior. fun. The coefficient parameters are defined as a random variable that follows Cauchy distribution with hyper parameter $(0 ; 2.5)$. The chosen Cauchy distribution and its hyper parameter are set based on Gelman et al. (2008).

Windowing scheme is used in this study to know in which period the model gives its best by reducing number of observations for one year backward. First window uses data of observation starting from 1990 until the end. Second window uses data of observation starting from 1991 until the end. It continues until 22-th window. The C-index value is calculated for each window to compare the performance of the proposed approach.

The first window contains observations from 1990 to 2015 with 5458 sample size. Number of burn-in using the improper uniform prior and Cauchy prior distribution is 5001. It is convergent or reaches steady state conditions in 5001-th iteration. The number of burn-in for multivariate normal distribution is 1001 . The convergent iteration for a multivariate normal prior distribution is obtained in 1001-th iteration. Based on number of burn-in, multivariate normal prior distribution is faster to achieve a convergent estimate value than other pr 
Table 2 Misappropriate sign of parameters estimates.

\begin{tabular}{ccc}
\hline $\begin{array}{c}\text { Prior } \\
\text { Distribution }\end{array}$ & $\begin{array}{c}\text { Significant } \\
\text { Variable }\end{array}$ & $\begin{array}{c}\text { Misappropriate Variable } \\
\text { w.r.t Financial Ratio Rule }\end{array}$ \\
\hline $\begin{array}{c}\text { Improper } \\
\text { uniform }\end{array}$ & $\begin{array}{c}\text { CR, GPM, } \\
\text { WCLTD, SFA, } \\
\text { IHSG, BI_Rate }\end{array}$ & CR, GPM, IHSG \\
$\begin{array}{c}\text { Multivariate } \\
\text { Normal }\end{array}$ & $\begin{array}{c}\text { CR, GPM, EBITA, } \\
\text { STA, SFA, } \\
\text { BI_Rate }\end{array}$ & CR, GPM, \\
Cauchy & CR, GPM, & \\
& WCLTD, IHSG, \\
BI_Rate & CR, GPM, IHSG \\
\hline
\end{tabular}

Parameter estimation for each prior distribution delivers significant variables within the model. Some of significant variables have sign that are not appropriate with financial ratio perspective. Table 2 shows misappropriate parameters estimates with their corresponding financial ratio rule. For all prior distributions, the parameters estimates corresponding to $\mathrm{CR}$ and GPM misappropriate the financial ratio rules. Therefore data windowing is important in order to reduce or remove this effect.

The performance of the model is evaluated using $\mathrm{C}$-index. It measures good sequence by resolving constraints and violations caused by miss ranking between observation pairs (Van Belle et al., 2010). The C-index value is calculated for each window and also for each prior distribution as listed in Table 3. The $\mathrm{C}$-index values resulted in from the improper uniform prior distribution are equals to the ones produced from Cauchy prior distribution. Formula of C-index is taken by sequence of survival time corresponding with probability of delisted. It ignores the survival probability and hazard value. Cindex values are constant overtime while the number of data observation decreases. Moreover, the $\mathrm{C}$-index values of improper uniform and Cauchy prior distribution are less than the $\mathrm{C}$-index values of multivariate normal distribution prior.

The highest C-index is obtained from 2-nd window until 7-th window when the multivariate normal prior distribution is used. Due to the smaller sample size gives the advantage for iteration and collecting the data, therefore the best model is obtained from the data that span from 1996 until 2015 with sample size is 4797.

Table 4 displays parameter estimator obtained from data in 2-nd window and multivariate normal prior distribution. The significant predictors are CR, GPM, EBITA, STA, SFA, IHSG, and BI Rate. Within the $95 \%$ confidence interval resulted in from $2.50 \%$ to $97.50 \%$ percentile of posterior estimates, the estimators do not contain zero. This means that these predictors are significant and shown by highlight. Three out of seven significant predictors do not meet financial ratio rule from corporate finance point of view. They are CR, GPM and IHSG that are indicated by bold italic. The values of CR, GPM and IHSG are positive value as follows $0.416002,3.879433$, and 0.001756 , respectively. This means that if the company lasted up to 103 quarters, then the company has a greater probability of delisting. The financial ratio theory explains that if values of CR, GPM and IHSG variables increase then the probability of delisted company decreases. This inappropriateness may be caused by multicollinearity.

The other significant variables are EBITA, STA, SFA, and BI Rate. The values of those corresponding coefficients are negative; i.e. $11.5796,8.2343,4.5078$ and 1.2798. Based on the financial ratio theory, those variables are appropriate with financial ratio interpretation. If the companies survive until 103 quarters, these companies have higher probability of being delisted. The addition of each unit of variable EBITA, STA, SFA, and BI. Rate causes the company's probability to delisting is smaller. Based on the estimation value listed in Table 4, the hazard value can be calculated to predict the potentially delisting company. The hazard model is formulated in Eq. (10). All predictors are written in the formula, because all the values have the influence for the delisting of company, even though its value is small.

$$
\hat{h}\left(t, x_{i}\right)=\frac{\hat{a}_{i t}}{1+\hat{a}_{i t}},
$$

with

$$
\begin{aligned}
\hat{a}_{i t}=\exp & -7.0123+0.4160 C R_{i t}+0.4704 D A R_{i t} \\
& -0.1188 D E R_{i t}-1.2810 R O A_{i t} \\
& -0.5921 \text { ROE }_{i t}+3.8794 \text { GPM }_{i t} \\
& -1.5396 \text { OPM }_{i t}+0.0760 N P M_{i t} \\
& -11.5796 E B I T A_{i t}-8.2343 T A_{i t} \\
& +0.3293 \text { ET D }_{i t}-0.2660 W C A_{i t} \\
& -0.0113 \text { WCLTD }_{i t}-0.4607 R E A_{i t} \\
& -4.5078 \text { SFA }_{i t}+0.0018 \text { IHSG }_{t} \\
& \left.-1.2798 \text { Brate }_{t}\right)
\end{aligned}
$$

The cumulative hazard is produced by summing up each probability of hazard for each company in first to the last quarter. Meanwhile, survival probability is calculated by using the relation of hazard function and survival function that has been described in Eq. (3). Probability of delisting company is calculated by subtracting one

\begin{tabular}{|c|c|c|c|c|c|}
\hline \multirow[b]{2}{*}{ Wind. } & \multirow[b]{2}{*}{$\begin{array}{l}\text { Year } \\
\text { Begin }\end{array}$} & \multirow[b]{2}{*}{$\begin{array}{c}\text { Sample } \\
\text { Size }\end{array}$} & \multicolumn{3}{|c|}{ Prior Distribution } \\
\hline & & & $\begin{array}{l}\text { Improper } \\
\text { Uniform }\end{array}$ & $\begin{array}{l}\text { Multivariate } \\
\text { Normal }\end{array}$ & Cauchy \\
\hline 1 & 1990 & 5458 & 44.1177 & 58.8235 & 44.1177 \\
\hline 2 & 1991 & 5434 & 44.1177 & 64.7059 & 44.1177 \\
\hline 3 & 1992 & 5353 & 44.1177 & 64.7059 & 44.1177 \\
\hline 4 & 1993 & 5245 & 44.1177 & 64.7059 & 44.1177 \\
\hline 5 & 1994 & 5119 & 44.1177 & 64.7059 & 44.1177 \\
\hline 6 & 1995 & 4969 & 44.1177 & 64.7059 & 44.1177 \\
\hline 7 & 1996 & 4797 & 44.1177 & 64.7059 & 44.1177 \\
\hline 8 & 1997 & 4616 & 44.1177 & 61.7647 & 44.1177 \\
\hline 9 & 1998 & 4421 & 44.1177 & 61.7647 & 44.1177 \\
\hline 10 & 1999 & 4221 & 44.1177 & 61.7647 & 44.1177 \\
\hline 11 & 2000 & 4020 & 44.1177 & 58.8235 & 44.1177 \\
\hline 12 & 2001 & 3812 & 44.1177 & 58.8235 & 44.1177 \\
\hline 13 & 2002 & 3596 & 44.1177 & 58.8235 & 44.1177 \\
\hline 14 & 2003 & 3370 & 44.1177 & 58.8235 & 44.1177 \\
\hline 15 & 2004 & 3138 & 44.1177 & 58.8235 & 44.1177 \\
\hline 16 & 2005 & 2902 & 44.1177 & 58.8235 & 44.1177 \\
\hline 17 & 2006 & 2666 & 44.1177 & 58.8235 & 44.1177 \\
\hline 18 & 2007 & 2426 & 44.1177 & 58.8235 & 44.1177 \\
\hline 19 & 2008 & 2183 & 44.1177 & 58.8235 & 44.1177 \\
\hline 20 & 2009 & 1916 & 44.1177 & 58.8235 & 44.1177 \\
\hline 21 & 2010 & 1648 & 44.1177 & 55.8823 & 44.1177 \\
\hline 22 & 2011 & 1376 & 44.1177 & 55.8823 & 44.1177 \\
\hline
\end{tabular}
by its survival probability. Based on (1), it calculates the probability of hazard, survives, and delisting for each company. Its descriptive statistic are summarized in Table 5.

Table 5 informs that there are companies that have hazard values of 0.3943 and 0 . Companies that have smaller hazard value will be safer to be invested because it has small probability to delist form IDX. Companies with large hazard value have small probability to survive and consequently have a high probability of delisting.

Table 3 The C-index value calculated for each window. 
Table 4 Parameter estimates obtained from data in 1996-2015 using multivariate normal prior distribution.

\begin{tabular}{|c|c|c|c|}
\hline \multirow{2}{*}{ Variable } & \multirow{2}{*}{ Mean } & \multicolumn{2}{|c|}{ Confidence Interval } \\
\hline & & $2.50 \%$ & $97.50 \%$ \\
\hline intercept & -7.0123 & -8.4080 & -5.6476 \\
\hline$C R$ & 0.4160 & 0.0783 & 0.7119 \\
\hline DAR & 0.4704 & -1.1390 & 1.8712 \\
\hline DER & -0.1188 & -0.4561 & 0.2081 \\
\hline ROA & -1.2810 & -6.0580 & 3.4872 \\
\hline ROE & -0.5921 & -3.1400 & 1.5589 \\
\hline GPM & 3.8794 & 0.6634 & 7.4113 \\
\hline OPM & -1.5396 & -3.5140 & 0.4874 \\
\hline NPM & 0.0760 & -1.0720 & 1.1237 \\
\hline EBITA & -11.5796 & -17.8600 & -4.8551 \\
\hline STA & -8.2343 & -12.6600 & -4.3605 \\
\hline ETD & 0.3293 & -2.4380 & 2.9549 \\
\hline WCA & -0.2660 & -1.9170 & 1.4325 \\
\hline WCLTD & -0.0113 & -0.0955 & 0.0635 \\
\hline REA & -0.4607 & -1.4870 & 0.4828 \\
\hline SFA & -4.5078 & -7.8470 & -1.6356 \\
\hline IHSG & 0.0018 & 0.0004 & 0.0033 \\
\hline BI Rate & -1.2798 & -2.4520 & -0.4020 \\
\hline
\end{tabular}

Table 5 Descriptive statistics of hazard, survival and delisting probability.

\begin{tabular}{lcccc}
\hline \multirow{2}{*}{ Probability } & \multicolumn{4}{c}{ Statistic } \\
\cline { 2 - 5 } & Mean & Min & Median & Max \\
\hline Hazard & 0.0231 & 0 & 0.0002 & 0.3943 \\
Survival & 0.9797 & 0.6742 & 0.9998 & 1 \\
Delisting & 0.0230 & 0 & 0.0002 & 0.3258 \\
\hline
\end{tabular}

\section{CONCLUSION}

In this work, the Bayesian multiple-period logit model is successfully applied to predict the default probability and survival probability of listed manufacture companies in Indonesian stock exchange. Among the three prior distributions employed, the most appropriate prior is multivariate normal distribution. This prior is able to update the information in the likelihood of the data such that the values of $\mathrm{C}$-index obtained are always higher than ones obtained from other priors. Moreover, the windowing scheme suggests the shortest period of data with highest C-index is the data span from 1996 until 2015. The significant predictors as input of the best model are CR, GPM, EBITA, STA, SFA, IHSG and BI Rate. Three out of these seven significant predictors, i.e. CR, GPM, and IHSG, have coefficients sign that opposite with financial perspective.

\section{ACKNOWLEDGEMENT}

This work is financially supported by Indonesian Ministry of Research, Technology, and Higher Education, through DRPM Grant under "Penelitian Fundamental" scheme with the first author as principal investigator under contract number 512/PKS/ITS/2017. Authors are gratefull to the reviewers for the corrections to improve the quality of this paper.

\section{REFERENCES}

Bender, R., Augustin, T., and Blettner, M. Generating Survival Times to Simulate Cox Proportional Hazards Models, Statistics in Medicine, 24, pp. 1713-1723, 2005.

Box, G. E. P. and Tiao, G. C., Bayeisan Inference in Statistical Analysis, New York: John Wiley and Sons, Inc., 1992.

Cole, R. A. and Wu, Q., Predicting Bank Failure using a Simple Dynamic Hazard Model, CFR Seminar Series Library, 2009.

Kleinbaum, D.G. and Klein, M. Survival Analysis : A Self-Learning Text, 3rd ed, London:Springer, 2012.

Gelman, A., Jakulian, A., Pittau, M. G., and Su, Y. S., A Weakly Informative Default Prior Distribution for Logical and other Regression Models, The Annals of Applied Statsitics, 2(4), pp. 1360-1383, 2008.

Mahjub, H., Faradmal, J., Goli, S. and Soltanian, A. R. Performance Evaluation of Support Vector Regression Models for Survival Analysis: A Simulation Research, Internationa Journal of Advanced Computer Science and Applications (IJACSA), 7(6), pp. 381-389, 2016.

Haerdle, W. and Prastyo, D. D. Embedded Predictor Selection for Default Risk Calculation: A Southeast Asian Industry Study, in Chuen, D. L. K. and Gregoriou, G.N. (Eds.). Handbook of Asian Finance, Vol. 1, Financial Market and Sovereign Wealth Fund, pp. 131-148 San Diego: Academic Press, 2014.

Iriawan, N. Report on the Establishment of Early Warning System (EWS) of Corporate Bonds (Original Title : Laporan Hasil Pembentukan Early Warning System (EWS) Obligasi Korporasi), Research Report, Surabaya: ITS, 2005.

Ismail, N. M., Khalid, Z. M., and Ahmad, N. Estimating Proportional Hazards Model Using Frequentist and Bayesian Approaches, Malaysian Journal of Fundamental and Applied Sciences, 8(2), pp. 73-82, 2012.

Khoiri, H. A., Prastyo, D. D., and Purnami, S. W. A Simulation Study and Application of Feature Selection on Survival Least Square Support Vector Machines, The 13th International Conference on Mathematics, Statistics, and Their Applications (ICMSA), Kedah, 2017.

Prastyo, D. D. and Haerdle, W. K. Localising Forward Intensities for Multiperiod Corporate Default, SFB 649 Discussion Paper, 2014-040, 2014.

Shumway, T. Forecasting bankruptcy more accurately: A simple hazard model, The Journal of Business, 74, pp. 101-124, 2001

Suhartono, Rahmawati, D., Atok, R. M., Prastyo, D. D. and Ahmad, I. S., Determinant Factors of Publication in Scopus at ITS, The 12th International Conference on Mathematics, Statistics, and Their Applications (ICMSA), Banda Aceh, 2016, pp. 144-148.

Van Belle, V., Pelckmans, K., Suykens, J. A. and Van Huffel, S. Additive Survival Least-Squares Support Vector Machines, Statistics in Medicine, 29(2), pp. 296-308, 2010.

Van Belle, V., K. Pelckmans, J.A. Suykens, and S. Van Huffel, Support vector methods for survival analysis: a comparison between ranking and regression approaches, Artificial Intelligence in Medicine, 53(2), pp. 107$118,2011$.

Wong, M. C. M., Lam, K. F. and Lo, E. C. M., Bayesian Analysis of Clustered Interval-Cencored Data, Journal of Dental Research, 84(9), pp. 817-821, 2005 . 